\title{
CLIENT SERVICE IN A DEFENDER ORGANIZATION: THE PHILADELPHIA EXPERIENCE*
}

Since 1934, the Defender Association of Philadelphia has provided representation for indigents accused of the commission of crime. In the wake of Gideon v. Wainwright ${ }^{1}$ and its progeny, the Association underwent significant expansion as it moved to represent every indigent criminal defendant in the city at every significant stage of the criminal process. Until a recent financial crisis, ${ }^{2}$ the Defender was supplying legal services to clients well beyond those so far held mandatory by the Supreme Court under the Federal Constitution.

Rapid expansion in the number of clients served and the breadth of representation supplied has resulted in considerable pressure on the staff of the office. During the period encompassed by this studyprimarily July of 1967-the Association's staff consisted of some thirty-six attorneys, supported by ten investigators, a social worker, and fifteen secretaries. ${ }^{3}$ In the single month of July, 1967, these thirty-

* This study was originally prepared for, and financed by, the National Defender Project of the National Legal Aid \& Defender Association, who have kindly permitted its publication here.

The authors would like to express their thanks to the many persons who contributed time and wisdom to this study. Prominent among them were Joseph $\mathrm{N}$. Bongiovanni, Jr.; Edward W. Madiera, Jr.; Bernard L. Segal; and Martin Vinikoor, members of the Philadelphia Bar; Herman I. Pollock; Vincent J. Ziccardi; Leonard Packel; Albert Branson; Melvin Dildine; George Johnson; Benjamin Lerner; William McDaniels; John Packel; and Isaac Pepp, on the staff of the Defender Association of Philadelphia; Joseph M. Smith and William F. Knatuer, on the staff of the Philadeiphia District Attorney's office; and Dr. Ronald Gulezian, assistant professor of statistics at Temple University. The authors, of course, bear full responsibility for any errors in the study.

\section{U.S. 335 (1963).}

2 The crisis began in the fall of 1968, when federal funds and a private grant that had been supporting a large part of the organization's services were terminated. Negotiations were begun with an eye towards obtaining full funding from the city. After the Mayor proposed that the city set up its own "Public Defender" as a part of the city government, a "compromise" was reached between the city and the Defender Association. Under the agreement, the city will provide the Association with $\$ 1.2$ million annually and will control the board of directors. The acting Defender of the Association, Martin Vinikoor, has already been forced to resign, but the City Solicitor has given assurances that the 19 attorneys who have survived the cut in funding will not be immediately fired. See ABA Project on Minimuar Standards for Criminal Justice, Standards Retating to Providing Defense Services $\$ 1.4$ (tent. draft 1967): Defender "plan and the lawyers serving under it should be free from political influence." See generally Philadelphia Bulletin, January 8, 1969, at 10, cols. 6-7 (Louis B. Schwartz: "compelled surrender" of Association's independence); id. January 10, 1969, at 40, cols. 7-8 (Philadelphia District Attorney: "pure and simple patronage

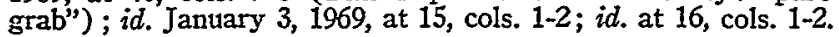

a Just prior to Gideon, the professional staff consisted of 6 lawyers. 
six lawyers "served" 1,854 clients." At least one major challenge (an unsuccessful one) has been mounted against Defender representation as being inadequate "Assistance of Counsel" for criminal defendants."

This study focuses on one objectively measurable aspect of Defender Association service to its clients: the amount of professional time received by the average client in a given type of case. While this factor is by no means determinative of the quality of representation, it is clearly relevant to it. Not only is it relevant, but it can be objectively measured, whereas many of the other elements relating to the adequacy of counsel in a particular case cannot. The data collected here can, it is hoped, provide a meaningful gloss to official statistics. In addition, in a time when the burgeoning demands of indigent criminal representation are taxing the foresight of every legal defense organization, it is hoped that the methodology here developed may be an adaptable tool for measuring this aspect of representation in other organizations across the country.

\section{Mechanics of Defender Office Representation}

The office begins its file on a case by interviewing the defendant soon after the case is assigned by the court clerk-the usual way in which the Defender receives clients. The interview is usually conducted by one of the staff attorneys, but occasionally is taken by a law student working in the office. Only rarely will the interviewing attorney try the case. Under the "zone" system of defense, described below, the trial attorney generally studies the file for the first time the day before the case is scheduled for trial. All required preparation beyond the initial interview-alibi notices, transcripts, pretrial motions, and interviews of witnesses-must be anticipated by the interviewing attorney ${ }^{6}$ and requested of the investigators on the appropriate form. All the files are reviewed by one of the senior attorneys in the office, usually the

4 Services Performed During July, 1967

Persons Served in Bail Cases

Persons Served in Prison Cases

Persons Served in Federal Cases

Persons Served in Magistrates Courts

Persons Served re Postconviction Problems

Advisory and Other Services

Persons Served by C.L.S., Inc., in Magistrates Courts

Persons Served by C.L.S., Inc., in Postconviction and Other Matters

Domestic Relations Services

[C.L.S., Inc., is Community Legal Services, Inc, an organization that funded part of the Defender's work.]

5 United States ex rel. Mathis v. Rundle, 394 F.2d 748 (3d Cir. 1968).

6 If the interview is taken by a law student, an attorney reviews it immediately to assure that the proper requests have been made. 
First Assistant Defender or his chief lieutenant, and then assigned according to one of the two systems of defense used in the office, "man-toman" or "zone."

\section{The Zone Defense}

The zone defense is a consequence of the immense caseload thrust upon the Defender. Under this system, attorneys in the office are assigned on a monthly basis to cover a particular courtroom. Such an attorney will handle whatever aspect of a given case appears in his courtroom during his tour of duty there. If assigned to one of the motions courtrooms, he will be arguing pretrial motions; if assigned to a trial courtroom, he will try all the cases ${ }^{7}$ coming to trial there during his tour of duty. In the so-called "prison rooms," in which defendants unable to make bail are tried, the Defender Office not unexpectedly represents most of the clients. In the "bail rooms," the Defender attorney will handle only a fraction of the cases, but is present and on call all day.

Attorneys on a zone assignment to a trial or motions courtroom generally obtained the file on the cases to be heard the evening before trial or hearing. The possibilities for preparation are obviously limited, and the adequacy of representation will depend in large part on the completeness of the file. Much of the pretrial preparation-interviewing and subpoenaing of witnesses, filing of alibi notices, motions to suppress, and so forth-will have been taken care of by other persons in the office, and unless an error has been made no substantial harm is likely to result. ${ }^{8}$ But any complex legal issues appearing at the trial will have to be researched the evening before, and personal contact with the defendant and the preparation of witnesses is limited to whatever time can be found for conversation in the cellroom, the courtroom or the halls outside.

\section{The Man-to-Man Defense}

At the time of this study, almost all cases in the office were handled according to the zone system, man-to-man assignments being limited to "major cases" " and those of particular complexity or importance to the defendant. ${ }^{10}$ Under the man-to-man system, a case is assigned (usually a short time after the initial interview) to a particular attorney, who below.

7 Except those being handled according to the man-to-man system, discussed

8 If it becomes apparent that such an error has been made, the attorney will of course normally ask for a continuance.

0 The District Attorney's Office has a procedure by which certain cases are designated "major cases." In addition to most homicides, at the time of the study all rape cases (except for some statutory rapes) and many cases of sodomy, indecent assault, or assault and battery with intent to ravish were so designated. All "major cases" are given man-to-man treatment by the Defender Association.

10 E.g., a first offense. 
then takes care of all the legal aspects of the case ${ }^{11}$ through conviction or acquittal; in many if not most such cases if an initial interview has been taken he will reinterview the client.

The advantages of the man-to-man system are considerable. In addition to the obvious benefit to the client, such a system is of considerable psychological benefit to the attorneys involved: their image of themselves as professional men with individual clients is naturally improved. At no time, however, has the staff of the office been sufficiently large to allow all cases to be handled on this basis. ${ }^{12}$ Nevertheless, subsequent to the period covered by this study the office instituted a program whereby all cases in which the defendant was unable to make bail-roughly half the total caseload ${ }^{13}$-were defended on the man-toman system. Other cases, except for "major cases," continued to be defended by zone.

\section{METHODOLOGY}

At the outset of the project, alternative methods for the study were examined and rejected. First considered was a statistical study based on representative segments of closed files on defendants served by the office. However, only the bare skeleton of the story is presented in a man's folder: the charges, plea, verdict, sentence, and the name of the lawyer or lawyers involved. If a pretrial motion was made and supported by a brief, that fact might be recorded elsewhere. Without detailed discussions with the staff and some method for assigning time values to the activities recorded on a folder, files could provide no answer to the question how much legal time had been devoted to individual clients.

A second alternative considered was to compose daily time sheets and questionnaires to be filled out by the lawyers; these could then be collated to arrive at the information desired. Although time sheets were anathema to the office, the possibilities they presented for obtaining precise data were alluring. But it would have been unrealistic to expect accurate recall from an attorney who had spent a tiring day in court, especially when such information is not needed to bill a client. ${ }^{14}$ Would any attorney remember how much time he had spent waiting before each case he had handled that day? Would any recall with any

11 Most of the investigatory work and interviewing of witnesses will still be done, however, by the investigatory staff.

12 Of course, all cases could be handled on a man-to-man basis simply by assigning each case to an individual attorney. Such a system would result in an impossible load for the individual defenders, and render the representation meaningless in many circumstances. The office has followed a practice that assures that no attorney is responsible for more than 40 cases at any one time.

13 During the 13 months ending June 30,1968, the office closed 2,322 prison cases and 2,324 bail cases after trial. Defender Association of Phinadelphia, 34th ANN. ReP. 20 (1968).

14 The office is reimbursed for cases handled in federal courts under 18 U.S.C. $\S 3006 \mathrm{~A}$ (1964), and keeps worksheets for such cases. 
precision how much time he had spent reading a newspaper or chatting with colleagues?

The third option - and the one adopted-was a system of direct observation applying a statistical sampling technique. ${ }^{15}$ At certain preselected times during each day of the sample month, each Defender attorney was observed to ascertain precisely what he was doing. The randomness of the observation times and the frequency of the observations are the keys to the validity of the methodology.

A system of direct observation was obviously more convenient for the attorneys than time sheets would have been. On many occasions, the attorneys involved were not even aware of the observer's presence. In many situations, however, the system still required a modicum of cooperation from the attorneys. While a defender could be observed writing at his desk, he had to be questioned in order to find out what he was writing. Here, some (understandable) unresponsiveness was encountered, which gave the method an unanticipated weakness in places. Because defenders were assigned to courtrooms on a weekly basis at the time of the study, a single uncooperative attorney could cloud observations in a whole area by rendering a quarter of them imprecise or even incorrect. When this problem occurred, observations had to be either recorded in a more generalized manner than planned, or else thrown out-which, of course, cut down on the sample size for the activity in question. Fortunately, this happened infrequently. In spite of these shortcomings, the method adopted did allow the study to proceed in a fairly objective manner. Minimum reliance on the personal memory of the subject attorneys was a paramount advantage.

The contours of the methodology were dictated by the geographical dispersion of the Defender Association's workload among several locations, chiefly the magistrates courts, city hall, ${ }^{16}$ and the office. The practical problem was for two persons to observe the daily activity of from 28 to 30 lawyers: during July 1967, the main sample month, the Defender staff included some 36 attorneys, several of whom were on vacation each week. Since all could not be observed simultaneously, a work-sampling technique seemed the only solution. The technique finally devised worked as follows.

The first phase of the study centered on the defenders at work in city hall and in the office. Toward the end of June, 6,000 random observation times were selected from a table of random numbersenough to be utilized during the twenty workdays included in the study. These times were assigned each day for observation by an observer in

15 This third alternative was derived from $R$. M. BARNES, Work SAMPLING 131-34 (1957), where the author summarizes P. Christiansen, Utilization of Professional Manpower in the Teaching Profession, - - 1955 (unpublished Ph.D. Thesis, Wayne University), a study of elementary school teacher work dispersion. The derivation involved modification of the method for a law office study, and addition of a procedure to determine average time per lawyer in the work dispersion categories.

16 The criminal trial courts in Philadelphia are located in the city hall. 
city hall or by one in the office, on the basis of (1) a regular attorney assignment pattern and (2) convenience of observation. Daily assignment sheets supplied by the office told what attorney would be where at a particular time, and on that basis a rotation pattern was devised to assure observation of each attorney at either location ten to fifteen times during the course of each day. Allocation of times on the basis of "convenience" meant that, for example, if two consecutive minutes were among the random times on the schedule for a particular day, both observations could not sensibly be assigned to the person sampling attorney activity in city hall, where an observation on the sixth floor might well be followed by one on the first. Thus, one minute would be allocated to the observer at city hall, and the other to the observer at the office. Whatever the attorney was doing would be directly observed and recorded at the designated, random time.

Prior to the study, the office's legal activity had been categorized. ${ }^{17}$ When these categories were supplemented by that of activity "Unallocated to Clients," any given attorney's activity could be placed within one of the categories on each occasion for observation.

Usable observations totalled 3,529. The distribution of these cbservations determined the distribution of aggregate professional hours among the categories of Defender activities recorded in Table $I$, below. Thus, ratios were developed for the incidence of checks in each category as compared with the total number of usable observations. These ratios represented the percentage of total defender time spent on each particular stage of the criminal process. The total number of man-hours for the month was calculated by multiplying the number of lawyers present during the workdays in July by the approximate number of hours worked by each. These totals were then divided by the number of clients served in each area ${ }^{18}$ to find the average amount

17 These categories are discussed in detail at pp. 458-68 infra.

18 Data were obtained from the Defender Office indicating the number of defendants served in each broad stage of the process, part of which is set out in note 4 supra. The data below, which breaks down the number of defendants represented at trial by the most serious offense for which each was under indictment, was compiled from an official tally of bills of indictment for each file closed by the office in July. Since this tally might list, for example, as many as 6 different bills of indictment for a single defendant, the bill carrying the highest potential penalty was used to obtain a single charge to ascribe to each defendant. Thus, a charge of assault and battery, sodomy, and rape was classified for our purposes as a rape charge. The categories were as follows:

1) Major Crimes of Violence-armed robbery, arson, assault with a deadly weapon, assault with intent to murder, etc. : 81 cases closed during July, 1967.

2) Sex Offenses-rape, most statutory rapes, serious cases of sodomy, indecent assault, assault and battery with intent to ravish, etc. : 17 cases closed during July, 1967.

3) Narcotics Offenses-sale, possession and use (it should be noted that the great majority of such cases in July were possession and use) : 37 cases closed during July, 1967.

4) Other Major Offenses-generally felonies, e.g., burglary, larceny, receiving stolen goods, larceny of a motor vehicle, assault and battery: 177 cases closed during July, 1967.

5) Sumptuary and Other Minor Offenses-Liquor Code violations, gambling, prostitution, etc. : 77 cases closed during July, 1967. 
of time spent per client in each activity. ${ }^{19}$ These averages were then combined to arrive at the average total amount of legal time received by a defendant served by the Defender Office at all stages of the criminal process from arrest through conviction or acquittal. ${ }^{20}$

The second phase of the study concentrated on the magistrates courts. Each week in July seven lawyers were assigned by the Defender Association to serve in each of the seven magistrates courts distributed throughout the city of Philadelphia. The office provided data on the approximate number of hours each attorney spent at each location on a given day, and from this was calculated the total number of man-hours spent in these courts during July.

Because the first phase of the study completely occupied the observers during the month of July, it was impossible to observe the magistrates courts directly at that time. However, the seven locations were continuously observed during two weeks in August. Each court was visited on two mornings, with the exception of the twenty-fourhour court located at the Police Administration Building, where all preliminary arraignments were then held. This court was visited five times.

This census of the activities in the magistrates courts, as contrasted with the sampling technique utilized in the Defender Office and at city hall, enabled the range of legal time the average client would receive in these courts to be ascertained. Members of the Defender staff indicated that the legal work performed at these courts in August was essentially similar to that in July. The discussion of the magistrates courts below assumes the applicability of these findings to the 1400 man-hours catalogued for this activity in July.

\section{RESULTS}

Tables I and II, presented on the following pages, tell much of the story. One particularly striking fact that appears from Table $I$ is that almost half a Defender attorney's courtroom time ( 47 per cent) is spent in simply waiting. Out of 967 man-hours spent in court, 456 were utilized to no evident purpose. ${ }^{21}$

Table II, which deals with the average time spent per client, may provide a useful yardstick for comparing one defender organization to another, or, alternatively, for comparing defender service to that provided by a private attorney. The comparisons, of course, can only be rough. Several factors in particular allow the Defender Association to spend less attorney time in providing full service to its clients than would a typical private practitioner. First, the specialization within

19 Under the textual discussions of the categories reported in Table II, the ranges of variation of time spent per client in each activity are indicated.

20 See Table II. Thus, Table II is essentially derivative. The computed averages were added to obtain aggregate hours.

21 This point is discussed more fully at pp. 462-63 infra. 
TABLE I

Attorney Work Dispersion-July, $1967^{\circ}$

Stage in Criminal Process

Magistrates Courts

Arraignment

Other Pretrial Proceedings ${ }^{b}$

Pretrial Motions

Research/Writing

Argument

Preparation for Trial

Office Interviews

Prison Interviews

Investigation/Letters

Review/Consultation

In Court

Waiting

Counseling $^{c}$

Trying

Sentencing

Post-Conviction

Post-Trial Motions

Prisoner Correspondence

Prison Visitation ${ }^{\mathrm{d}}$

Direct Appeals

PCHA ${ }^{\circ}$ Petitions

Other Writs

Probation and Parole

Other Services ${ }^{\mathfrak{p}}$

Unallocated to Clients

Administration

Daily Reports

Staff Meetings

Personal/Absence

Unknown

Totals

\begin{tabular}{rr} 
Man-Hours & \% of Total \\
\cline { 2 - 2 } 1400 & 26.8 \\
56 & 1.1 \\
58 & 1.1
\end{tabular}

72

82

1.4

$154 \quad 1.5$

2.9

152

2.9

174

3.3

32

318

676

0.6

6.1

12.9

456

91

8.8

1.7

7.0

52

967

1.0

18.5

96

1.8

0.8

4.2

3.0

2.9

153

75

740

1.4

14.1

108

2.1

104

2.0

a confidence level of $90 \%$ has been used as the minimum per category for all statistics. Some of the categories, such as "In Court," achieved higher confidence than others that suffered because of small sample sizes.

b Includes bench warrants, extradition hearings, and hearings before the United States Commissioners.

c With client or another attorney.

d Includes time spent traveling to and from prisons.

e Post Conviction Hearing Act, PA. STAт. ANN. tit. 19, \$§1180-1 to -14 (Supp. 1967), a broad substitute for habeas corpus.

f Includes attachment proceedings, juvenile proceedings, and mental health commitment proceedings.

(5 This total includes only hours worked from 9:00 a.m. to 5:30 p.m. each day, with the exception of the total for the magistrates courts, where actual shifts ran through the night and on weekends. There was no accurate way of measuring hours spent by attorneys on client work in the evenings. 
TABLE II

Average Legal Time (in Minutes) per Defendant from ARREST to Conviction or AcQUITTAL ${ }^{\text {h }}$

Magistrates Courts

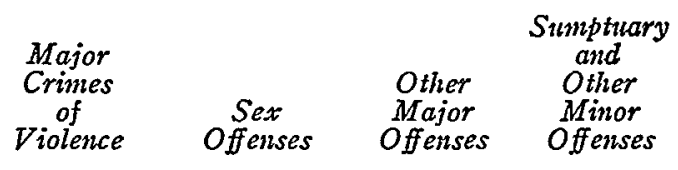

Preliminary Arraignment

$\begin{array}{cccc}8 & 8 & 8 & 8 \\ 15 & 15 & 15 & 15 \\ 2 & 2 & 2 & 2 \\ & & & \\ 45 & 45 & 45 & 45 \\ 87 & 214 & 35 & 26 \\ & & & \\ 102 & 150 & 58 & 51 \\ 14 & 46 & 12 & 16 \\ 57 & 390 & 44 & 32 \\ 9 & 60 & 6 & 5 \\ & & & \\ 339 & 630 & 225 & 200 \\ 5 \text { hours } & 10 \text { hours } & 3 \text { hours } & 3 \text { hours } \\ 39 \text { min. } & 30 \text { min. } & 45 \text { min. } & 20 \text { min. }\end{array}$

$\mathrm{h}$ This table is a compilation of data reported in the textual explanations of table I, at pages 458-68 infra. Eliminated from this table is any tally of the average amount of time spent on services not performed for the typical defendant going to trial, e.g., pretrial motions and appeal and postconviction services. Furthermore, since the sample size for narcotics cases was small, the figures for those offenses are not incorporated into this table.

i The uniformity in the figures for this category is apparent, not real: time spent in magistrates courts and in interviewing was not categorized by type of offense.

$j$ Counseling includes discussions between attorney and client or between the defense attorney and another attorney, for the defense or prosecution.

$k$ Trying includes any activity performed while present at court at trial other than activity related to the sentencing pronouncement. This therefore includes such activities as motions for new trial, that are ordinarily made directly after the verdict in order to protect the record should the defendant appeal.

the office allows in many instances more efficient utilization of time, especially as compared with a private attorney handling criminal cases only a part of the time. Second, and particularly important, the Association has a full-time staff of investigators, who take care of the vast bulk of witness interviewing and investigatory work. Few private attorneys can afford such services. And finally, in considering the figures in Table II, it is worth remembering that no attempt was made to estimate time spent by an attorney in preparation at night or on weekends. Such work is fairly common, but there appeared to be no reliable way of estimating the amount of time actually spent. No such time is therefore included in Table II, and consequently the figures 
shown for work such as review and preparation for trial are probably somewhat smaller than the amount of time actually spent.

Recognizing the limitations necessarily inherent in any comparison of the figures here presented with the time spent on individual cases by private practitioners, it was nevertheless felt worthwhile to submit an informal questionnaire to a number of established attorneys in private criminal practice in Philadelphia. The questionnaire asked these attorneys to estimate the time they normally spent on behalf of a client (1) at the police station and magistrates court; (2) in pretrial activity, including preparation on the facts and the law, motions, negotiation with the district attorney, and continuances; and (3) at trial.

Few of the attorneys responding indicated that they would normally become involved at the earlier stages of a case, where the client is interviewed and fingerprinted by the police and taken to preliminary arraignment. $^{22}$ The time spent at magistrates court averaged close to two hours for all the lawyers responding to the questionnaire. This figure refers primarily to the preliminary hearing and includes time spent in travel to and from the court and in waiting in court. The time spent on pretrial procedures was variously estimated between five and eighteen hours. Time spent for non-jury trials varied from an average of four to an average of eight hours (exclusive of waiting, traveling, and sentencing time). Time spent at the sentencing stage averaged from one-half to three hours. Their estimates also indicated that time spent waiting and traveling at the trial stage generally amounted to about as much time as was spent in court trying a case. The lawyers indicated, additionally, that their less fortunate, marginal brethren would usually spend about half the indicated time at any level of the process.

In view of the division of labor at the Defender Office, it is not surprising that the time picture for Defender performance of these services shows lower totals than the subjective estimates informally gathered from private practitioners. ${ }^{23}$ In fact, Table II indicates that the time totals are strikingly lower. For instance, the average defendant charged with a nonviolent major offense (such as larceny) received about three hours and forty-five minutes of legal time from magistrates court through sentencing. This includes an average of an hour and twenty minutes for all pretrial preparation.

Although these figures may appear to be unrealistically low, their plausibility is reinforced by recent (albeit less formal) studies. The New York Times not long ago stated, "The opposing lawyers in Criminal Court-an assistant district attorney and usually a young defense lawyer provided free of charge by the Legal Aid Society-may have 5 to 10 minutes to study a case before arraignment." 24 A Bronx

22 Local rules of court allow the Defender Association to represent defendants at preliminary arraignment, and it regularly does.

${ }_{23}$ It would not be surprising if subjective estimates were slightly high.

24 N.Y. Times, Feb. 12, 1968, at 44, col. 5 . 
prosecutor was quoted as saying that "fifteen minutes to prepare a case would be a luxury." 25 According to the author of the article, about seventy-five per cent of the defendants in Manhattan are represented by lawyers from the Legal Aid Society. Some court administrators and lawyers, he continues, "see the Legal Aid Society as just another cog. in the Criminal Court apparatus and they contend the Legal Aid lawyers join in the general effort to get through the calendar as quickly as possible, regardless of whether justice is being done." 26

While metropolitan New York's problems may be of greater magnitude than Philadelphia's, on many occasions the time devoted to an indigent's entire defense was only a few minutes. On the other hand, some individuals-such as those involved in test cases-received as much as 100 hours of legal time. While both extremes were encountered, the conclusions here represent averages within the ranges of variation that are indicated in the text that follows.

\section{Specific Services Provided}

\section{Magistrates Courts}

At the time this study was conducted, early stages of the criminal process in Philadelphia were divided between six divisional courts and a twenty-four-hour Central Magistrates Arraignment Court located in the Police Administration Building (PAB). To this group must be added, for the sake of convenience, the comparable service provided in the Philadelphia County Court, which in jurisdictional terms is not a magistrates court. Table III depicts the dispersion of Defender Office workload among these courts in the two legal proceedings conducted there-preliminary arraignments and preliminary hearings.

A defender was present at the central court around the clock, seven days a week, in eight-hour shifts. The defendant is processed in the PAB, and can thus be brought before a magistrate directly after processing for a preliminary arraignment. As Table III shows, all preliminary arraignments (with the exception of juvenile cases, handled at 1801 Vine St., and an unexplained maverick at 17th and Montgomery) take place at the PAB. As noted before, the Defender represents nearly all defendants at this stage of the process, even though private counsel may later be secured.

The Defender's function here is primarily to obtain a fair bail and, sometimes, to request an immediate preliminary hearing when it is obvious that the charge cannot be made out. To propose fair bail the attorney must have some knowledge of the defendant-the length of his residence in the community, family ties, and so forth-as well as of the charge. Theoretically, this would require an interview. As often as not, there was none; the defender would stand beside his client for a

$25 I d$.

26 Id. at col. 6. Cf. A. Blumberg, Criminal Justice (1967). 
TABLE III

Defender Office Magistrates Court Statistics-July, 1967

Location

1801 Vine St.

Germantown \& Haines

17th \& Montgomery

Germantown \& Montgomery

61st \& Thompson

55th \& Pine

Levick \& Harbison

8th \& Race (PAB)

Totals
Preliminary
Arraignments

18

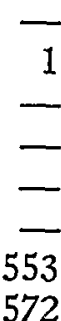

Preliminary Hearings

31

44

117

78

107

41

9

253

680
Summary

Offenses ${ }^{1}$

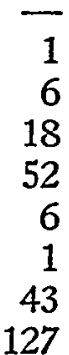

1 Cases where dismissal or fine was obtained.

few minutes and obtain whatever information he could through questions whispered in the defendant's ear. Because the magistrates seldom exercise independent judgment, ${ }^{27}$ creativity is discouraged. Their most common question was, "What do you think, Mr. District Attorney?" In the face of this, the Defender's job seemed to be to convince the prosecutor that his initial recommendation was too high. Against adverse odds, the Defender managed to get bail lowered in several cases each night.

Since any preliminary hearings in the central court took place between 9:00 a.m. and 4:00 p.m., the other two eight-hour shifts were relatively slow except on Friday and Saturday nights, when alcoholic consumption reaches weekly highs. An average of 8 to 10 preliminary arraignments took place during this shift from midnight to 8:00 a.m., each lasting from 5 to 10 minutes. This left 6 or 7 hours during which the attorneys on duty had little to do, although some occasionally worked on briefs or pretrial motions for other cases.

There was little variation in the length of preliminary hearings in the several courts; the only operative distinction was that, when added together, they seldom took more than 3 hours a day at any location except for the PAB. Defenders at preliminary hearings hope for one of two things: discovery or dismissal. In the month of July they succeeded in the latter aim 248 times. It is more difficult to determine how successful they were at the former, but some observation on time spent may give an indication of the depth of discovery.

The range observed in cross-examination at these hearings was 5 seconds to 30 minutes. The 30 -minute cross-examination, the kind that ruffles a magistrate's unjudicial feathers, was a searching inquiry of witnesses to an alleged robbery. Generally, the time taken at any particular hearing can be said to vary in proportion to its utilization by

27 Almost no magistrates in Philadelphia are lawyers. 
the defense as a discovery device. Such a technique usually requires prior interviewing of the defendant. These interviews, when taken, seldom lasted more than 5 minutes; the longest was 10 minutes. ${ }^{28}$ In that time, a defender could glean an idea of what to aim for in discovery or whether the case was appropriate for immediate dismissal.

\section{Other Pretrial Proceedings}

At arraignment, where trial date is set, Defender attorneys took at most 2 minutes with each defendant. They would give him a card bearing the office address and phone number and urge him to go there an hour later for an interview. At "Major Case Arraignment," when trial dates for major cases are listed, the conversation between attorney and client was only slightly longer.

Bench warrants are issued when a bailed defendant fails to appear at his arraignment. $\mathrm{He}$ is then brought before the trial commissioner who has power to "recommend" incarceration, which is to say that he has the power to put the man in jail. In these cases, it was observed that the defender assigned to handle bench warrants would take from 5 to 15 minutes in an attempt to highlight mitigating circumstances that might persuade the commissioner to lift the warrant and reinstate bail.

Hearings before the United States Commissioner are the federal counterpart to preliminary hearings in the state courts, albeit with a more judicial atmosphere. The Defender's appearances here were less frequent but more time-consuming than those in magistrates courts.

No extradition or detainer hearings were attended during the study period. There is consequently no range of time obtained for these stages of the process, although the total amount of time spent in these activities is included in the calculations for Table $I$.

\section{Pretrial Motions}

The sample size for this category was insufficient for a fine breakdown of activity in the area. It is helpful, however, to relate some general observations. The office typically uses a printed form for motions to suppress; it states simply that the defendant's constitutional rights have been infringed. Often a defender would have a secretary type in the necessary factual information. Recurrent violations of the fourth, fifth and sixth amendments by the Philadelphia police make it possible for briefs in support of certain pretrial motions to be merely statements of fact buttressed by familiar citations. Complete briefs for lower state courts were not infrequently written in 45 minutes or an hour. Of course, the degree of specialization in the office is in large part responsible for the speed with which briefs can be completed. One attorney in particular has utilized the natural advantage of the large

28 Some clients come into the office before preliminary hearing and are interviewed at length then. 
organization and the possibilities of division of labor by establishing routine methods for handling similar situations.

Since approximately 100 pretrial motions were filed monthly at the time of the study, the Defender provided an attorney to argue them nearly every day. These arguments seldom took more than 30 minutes, but at least half of the 4 hours typically spent daily in the motions courtroom would be spent not in argument, but in waiting. ${ }^{29}$

\section{Preparation for Trial}

Ninety-five per cent of the preparation by Defender lawyers for trial took place in one of two stages: interviews, usually with the client, either two weeks (prison) or two months (bail) before trial, and review and consultation immediately before trial. Between the interview and the trial, almost all of the investigation is handled by the office's investigatory staff. As indicated above, the interviewing attorney requests the investigators to interview witnesses, obtain hospital reports, file alibi notices, and so forth, on a form filled out at the time of the interview. Whether any such requests are made depends on the interviewing attorney's estimate of necessity. Time spent per case by investigators ranged from minutes to days. Rarely would an attorney accompany an investigator or do any investigation himself. During the study period, attorney investigation accounted for less than 3 per cent of total attorney preparation, and of the hours represented by that percentage, $\delta$ (just under half the total) were spent by one attorney working on a major sodomy case listed for its third trial in September.

The Defender interview form, on which all interviews are recorded, requires comprehensive personal information from the defendant. Among other things, it calls for a description of the arrest; defendant's sobriety at the time; weapons (if any) possessed; tools or proceeds of the crime; resistance to the arrest; and the names of any witnesses to the crime or arrest. Boxes at the end of the form can be checked in case the defendant has an alibi or if a motion to suppress may be made because of an illegal search or seizure.

The information contained on the form is the heart of all but major cases. Supplemented in most cases only by brief conversations with the defendant, the trial attorney must make his case from the information on the form. Interviews would rarely last longer than an hour; the average length during July was 45 minutes, and quite a few took only half an hour. Interviews did not appear to vary in length according to the offense involved, but rather with the articulateness of the defendant and the astuteness of the interviewer. If the interviewer was a law student, the interview would most likely approach the maximum length, but this of course did not mean that the interview would be extremely useful later.

29 No hearings on the voluntariness of confessions could be observed: under a local rule of obscure reason and dubious constitutionality, they are closed to the public. 
Thorough review of the files just before trial is obviously crucial to an adequate defense, particularly since in almost all cases the trial attorney would not have taken the interview. The attorneys usually take files on their cases home with them the night before trial. Conversations with some attorneys indicated that time spent per week outside of normal office hours ranged from 5 to 15 hours, but only when an attorney was assigned to a trial courtroom. The figures, however, were not amenable to any direct verification, and some skepticism may be appropriate. Table IV reports findings on the basis of daytime work hours only.

\section{TABLE IV}

Average Pretrial Review and Consultation Time per Defendant-Julx, 1967

Crime

Major Crimes of Violence

Sex Offenses

Narcotics Offenses ${ }^{m}$

Other Major Offenses

Sumptuary and Other Minor Offenses
Time (minutes)

87

214

16

35

26

m Subject to significant error: small sample size.

It should be remembered that "consultation" was defined to include discussion of the case with the district attorney as well as fellow defense attorneys. The high average for sex offenses reflects the fact that such offenses are almost invariably designated as major cases by the District Attorney's Office. Correlating these figures with the number of defendants in each category, ${ }^{30}$ the modal time for review and consultation appears as 35 minutes per defendant.

\section{In Court}

The time spent per client in court is indicated in Table V. One might assert that "waiting" time should not be allocated to a particular case since nothing is being done for the defendant in court at that moment. This is not certain. Although an attorney sitting in court might appear to be doing nothing, he could well be planning how to handle the next case. In any event, since it was impossible to arrive at empirical certainty, a presumption was indulged in. Unless the attorney was palpably not doing so, it was presumed that he was working on the next case on his list.

\section{Waiting}

Waiting accounted for just under half the Defender's courtroom time -47 per cent. Although the inefficiencies of trial administration 
TABLE V

Average Time per Defendant in Court-July, 1967

\begin{tabular}{|c|c|c|c|}
\hline $\begin{array}{l}\text { Minutes } \\
\text { Waiting }\end{array}$ & $\begin{array}{c}\text { Minutes } \\
\text { Counseling }\end{array}$ & $\begin{array}{c}\text { Minutes } \\
\text { Trying }\end{array}$ & $\begin{array}{c}\text { Mimutes } \\
\text { Sentencing }\end{array}$ \\
\hline \multicolumn{4}{|l|}{ Major Crimes of } \\
\hline Violence & 14 & 57 & 9 \\
\hline Sex Offenses $\quad 150$ & 46 & 390 & 60 \\
\hline Narcotics Offenses $^{\mathrm{n}} 27$ & 4 & 14 & 5 \\
\hline \multicolumn{4}{|l|}{ Other Major } \\
\hline Offenses $\quad 58$ & 12 & 44 & 6 \\
\hline \multicolumn{4}{|l|}{ Sumptuary and Other } \\
\hline Minor Offenses $\quad 51$ & 16 & 32 & 5 \\
\hline
\end{tabular}

affect all lawyers, the practice of making defenders wait until all private attorneys present have finished their cases particularly aggravates the situation for the office.

It is profitable to view waiting time in connection with the administrative listing of the case. For instance, the Defender's minor cases-those usually tried under the "crash program" 31-were inevitably tried at the end of the day. A defender would thus have to wait up to 6 hours before he could try a batch of 3 to 10 cases; however, he would have to remain in the courtroom the entire day, on the chance that there might be a gap in the array of paid counsel, in which case one or two of his clients might be squeezed in.

In the prison rooms, the defenders spend little time waitinglogically enough, because the Association represents most defendants who cannot make bail. But in the bail rooms, the situation was much like that in the minor case room-a long morning wait followed by trial of several cases in the afternoon. Much time was also spent waiting in major cases. This appeared to be due to the inefficient procedures at the courthouse. All major cases were assigned to courtrooms on the morning of trial. Both prosecutors and defenders would gather in a room in front of the trial commissioner and wait for a courtroom and judge. This procedure generally took 30 to 45 minutes in a chaotic atmosphere that made the wait valueless in terns of the defendant's representation. ${ }^{32}$

31 The "crash program" is a program under which, by consent of the District Attorney and the defendant, certain cases are tried on stipulated facts. Few of these defendants are imprisoned; fine or acquittal is the most common result.

32 Subsequent to the study period, a pretrial conference procedure was instituted for major cases. Each afternoon, up to 20 of the next day's major cases are reviewed by a judge and opposing lawyers to determine if they are ready to proceed. Philadelphia Bulletin, April 18, 1968, at 9, col. 3 . 


\section{Counseling}

This category represents the time defenders were observed talking with clients or other attorneys (prosecution or defense) immediately before or during trial. This would usually take place in the courtroom, although occasionally the defender would talk with his client in the hallway. The large amount of time shown for such activity for sumptuary and other minor offenses stems from the necessity for chatting with the defendant to differentiate his case from the morass of similar ones. Some of the consultation with prosecution attorneys may have been for the purpose of last-minute plea bargaining; there was, unfortunately, no way to check this.

\section{Trying}

Except for sex offenses, in non-minor cases an average of 45 minutes to an hour of time was spent by defenders in trying the case in the courtroom. But in many cases, minor or not, this category may not be particularly meaningful. Stipulations of fact in minor cases can make the proceedings primarily a matter of sentencing. And of course, when the "trial" consists of nothing more than the entrance of a guilty plea, the proceedings are understandably brief.

The figures for sex offenses, again, are high because these cases were almost always designated by the district attorney as major cases and, additionally, were usually tried to a jury. It should be noted that the average of 6.5 hours allocated to such cases means, operationally, about a day and a half of trial. Jury trials were not normally taken in cases involving other offenses.

\section{Sentencing}

A separate category for sentencing, though theoretically meaningful, appears to be somewhat less valuable in practice. The definition used was that sentencing began once the verdict was announced and the judge began listening to argument over mitigating circumstances. But several factors make conclusions based on these statistics less than fully meaningful. First, time spent in bargaining out a plea $^{33}$ is primarily time spent bargaining out a sentence. Second, the existence of a good presentence report may require an attorney to spend less time at the hearing on sentence than would otherwise be required. Although presentence reports are the rule in sex cases, sentencing is much more complicated since the courts treat such offenders gingerly, believing that the psychological element is more significant here than anywhere else. $^{34}$ In the busy list courtrooms, however, much of the legal sparring is done on the spot.

33 When this is done.

34 See also Comment, Probation in Philadelphia: Judicial Decision and Constitutional Norms, 117 U. PA. L. REv. 323, 340 (1968). 


\section{Postconviction Services}

The 16 per cent of Defender time spent in postconviction work is dispersed over a wide variety of services. Four categories of activity, however, account for over 75 per cent of this time-prison visitation, direct appeals, PCHA petitions, and probation and parole--and it seems most profitable to confine discussion to them.

\section{Prison Visitation}

One defender specialized in prison visitations. Once (sometimes twice) a week, he traveled to the Eastern State Penitentiary, the maximum security state prison located in Philadelphia, where he spent most of the day. At least once every three months, he visited all of the state's prisons, interviewing all prisoners convicted in Philadelphia who wished to see him. Such a ride was taken during July and may have inflated the figures for this category well above the normespecially since, for the first time, he was accompanied by another attorney. This attorney met prisoners in two ways: in a group on one day and individually the next. He first addressed the new arrivals from every county at an orientation session, telling them who he is and making clear his availability every week to answer questions about any legal problems. Eighty-three prisoners attended four such orientation sessions in July. An observer accompanied this attorney to Eastern State Prison one day and observed his work directly. A log of the attorney's activity was kept, and is reproduced on the following page.

The attorney described this particular visit as typical. As the log shows, the range of time per prisoner was 5 to 15 minutes, and the range of topics discussed was what one might expect. Time spent was completely dependent on the prisoner-no one was ever rushed along. In addition to answering specific questions and assisting in specific procedures, the attorney provided an invaluable service-he acted as a safety valve. A surprisingly large number of prisoners who had arrived as Hotspurs left seemingly satisfied and relieved. In all, the attorney served 191 prisoners individually in July (including those visited on the circuit ride); a second attorney, in connection with probation and parole work, visited 73.

\section{Direct Appeals}

Griffin v. Illinois, ${ }^{35}$ Douglas v. California, ${ }^{36}$ and their Pennsylvania progeny ${ }^{37}$ have had a marked effect on the Defender's postconviction services. While not much more than three years ago Defender appeals were rare, during 1967 over 100 briefs were filed, an average of more

35351 U. S. 12 (1956).

36373 U.S. 353 (1963). (1966).

37 E.g., Commonwealth ex rel. Newsome v. Meyers, 422 Pa. 240, 220 A.2d $\$ 86$ 


\section{TABLE VI}

Time Log for Defender Prison Visit

\section{Minutes Spent}

15

15

10

5

15

10

15

5

15

5

5

15

10

5

10

5

15

10

5

5
5
5
15

\section{Item}

Sentence correction

Resentencing

Filing appeal; general gripes

Followup on resentencing inquiry

General counseling

General counseling

Filling out appeal forms

Questions re appeal

Filling out appeal forms

Progress of appeal

Progress of appeal

Filing appeal

General counseling

Waiver of appeal

General counseling

Questions on parole

PCHA petition

Questions on parole

Concerning acquisition of notes

of trial testimony

Same

Question of time-in credit

Question on sentencing

In hospital, with violent patient, vainly trying to determine why he had been asked to come.

than 8 a month. In addition to filing in both Pennsylvania appellate courts, the Defender that year filed its first petition for certiorari to the Supreme Court of the United States. ${ }^{38}$ The head of the appeals section did most of the appellate brief writing, with one other attorney in particular doing a considerable amount of such work. Other defenders occasionally assisted. Although during the study month none of the Pennsylvania appellate courts heard argument, 10 briefs were filed, each requiring an average of 15.5 man-hours of research and writing time.

\section{PCHA Petitions}

The Pennsylvania Post-Conviction Hearing Act of 1966 "establishes a post-conviction procedure for providing relief from con-

38 Fairhurst v. United States, 388 F.2d 825 (3d Cir.), cert. denied, 392 U.S. 912 (1968). 
victions obtained and sentences imposed without due process of law." 39 As a rule, the prisoner triggers the procedure by submitting a petition requesting a hearing. At this hearing he usually meets a defender for the first time. If the hearing discloses a basis for relief, the Association will write a brief on the merits of the prisoner's case. The office represented about 75 prisoners at these initial hearings during the month under study; each hearing lasted about 30 minutes. The 4 briefs submitted as a result of these hearings required an average of just over 14 legal hours each for research and writing.

\section{Probation and Parole}

The Defender had one attorney who specializes in probation and parole work. Besides visiting prisoners every month, she also prepared and filed parole and reparole petitions. She occasionally attended the hearings on these petitions. In the study month she filed 7 such petitions, requiring some 91 hours of research and writing time. The time allocated to this activity in Table $I$ involved appearances at hearings as well as office work.

\section{Other Services}

Of the three classes of proceedings grouped under the heading "Other Services," (attachment, civil commitment, and juvenile work), attachment proceedings are by far the most time-consuming, taking as a whole 75 per cent of the time listed for the category. These proceedings typically arise when a divorced husband fails to provide support under a court order and is charged with contempt, punishable by up to 60 days in jail. The proceedings can drone on, sometimes taking as long as an hour and a half. The attorney assigned to the County Courthouse at 1801 Vine Street, where all such cases are heard, also serves at preliminary hearings in sex cases involving juveniles either as victim or defendant, which are also heard there. Activities tallied under the category "Other Services" also include interviews and correspondence with persons who were not ultimately represented by the Defender.

\section{Unallocated to Clients}

This category, accounting for 18.5 per cent of the total workday time, is self-explanatory. "Daily Reports" refers to summaries of magistrates court work, submitted by all attorneys assigned to these courts, and also to memoranda prepared for the files.

Attention might be called here to the fact that 75 per cent more time is spent waiting in court than in the administration of the office. Administration includes attorney time spent on such things as preparing

39 PA. STAT. ANN. tit. 19, §1180-2 (1966). 
list assignments, personal conferences, public relations work, reviewing of files for possible conflicts of interest in representation of two or more clients, formulating model legislation or test litigation, and innumerable other activities that benefit all clients generally but none in particular. Additionally, the Defender provides occasional assistance to members of the private bar and other organizations, and these activities are included in this category.

\section{CONCLUSIONS}

To a great extent the figures must speak for themselves. Meaningful comparison can be made only with other data similar in scope and similarly compiled. A number of observations, however, are pertinent here.

There has been considerable discussion in recent years concerning guilty plea bargaining. ${ }^{40}$ As already noted, no direct observation of the frequency of this practice could be made. Insofar as it did take place, it would have been allocated to the categories of "preparation for trial" or "counselling" at trial.41 Other evidence, however, indicates that it is not particularly frequent. In the city of Philadelphia, only about 27 per cent of all criminal cases are settled by entrance of a guilty plea; ${ }^{42}$ the Defender Association apparently enters even fewer such pleas for its clients: during the 13 months ending June 30,1968, of 4646 cases closed in state courts after trial, only 17 per cent were closed as a result of guilty pleas. ${ }^{43}$ Apparently, a Defender client is even more likely than the Philadelphia norm to want his case brought to trial.

A second observation is on the relative value of the two types of defense: man-to-man and zone. Whatever the overall view one may take of the time spent per client as indicated in the tables, it should be clear that the zone defense is one that should be resorted to only when absolutely necessary because of the pressures of time and resources. Even in an organization as small as the Defender Association, communication will frequently be imperfect. Initial interviewers may inadvertently omit material from the interview report, or may present it in a manner clear to them but confusing to the attorney who must rely on it at trial or at sentencing. When the attorney who has taken the interview is trying the case, the second danger is eliminated, and the first is minimized: everyone is familiar with the memory-jogging effect of even an incomplete record of prior events. Furthermore, a man-

40 See, e.g., Note, Judicial Plea Bargaining, 19 Staw. L. Rev. 1082 (1967); Note, Official Inducements to Plead Guilty: Suggested Morals for a Marketplace, 32 U. CEI. L. REv. 167 (1964). The most comprehensive treatment of the process to date is that contained in D. Newman, Conviction: The Deternination of Guilt or Innocence Without Trial (1966).

41 See text at pp. 461-62 supra.

42 Specter, Book Review, 76 Yale L.J. 604, 605 (1967).

43 Defender Association of Phil.adeiphia, 34th Annual Report 20 (1968). 
to-man system has additional, and valuable benefits. It substantially improves the professional self-image of the attorney involved; he is not a link in a chain, but rather the professional man responsible for a client's case. Finally, such a system reduces the danger, ever-present in regular criminal practice, that the attorneys will assume a role in the court system that leads them to seek not the best resolution for each individual client, but rather the best possible working relationship with the judges and courtroom officials. Such a phenomenon has frequently been noted elsewhere. ${ }^{44}$ Although it is doubtless impossible to guard completely against this danger, the Association has taken a number of steps to minimize it. Beginning in June of 1968, all cases in which the defendant had not been able to make bail were assigned to an individual attorney for all stages of preparation and for trial. This single step has meant that more than half of the clients represented at the trial stage by the office are represented by a single attorney from interview through trial. In addition, the observations made during the course of this study tend to support a belief that even attorneys assigned not by case but by courtroom are willing to press matters as hard as necessary when the situation warrants. Particularly common, for example, is the sight of a Defender attorney forcefully insisting on a jury trial before a judge whose dislike of such procedures is all too clear, or doggedly making a record for appeal despite obvious judicial impatience.

Mass representation in the United States is a recent development. Few if any standards have been developed by which to judge the adequacy of representation, let alone techniques to measure the standards. At present, the overwhelming constraint under which all such organizations must operate is the limited availability of funds; their primary problem, how best to allocate those funds. Resources must be allocated as wisely as possible to provide maximum return on an invariably inadequate investment. It is hoped that this study will provide a methodology adequate for some phases of the necessary investigations.

44 E.g., A. Blumraerg, Crimrnal Justice (1967) ; Platt \& Friedman, The Limitations of Advocacy: Occupational Hazards in Juvenile Contrt, 116 U. PA. L. Rev. 1156, 1176-81 (1968) ; Sudnow, Normal Crimes: Sociological Features of the Penal Code in a Public Defender Office, 12 Socins Probleass 255 (1965). 